think, to a small-type appendix ; after all, there must be some limit to a subject which, like forensic medicine, reaches for support into so many other departments of both science and medical practice.

Glaister remains a fine textbook, a sound piece of writing, well documented from the current literature, extensively illustrated by case reference, balanced and authoritative. It is a book for the advanced student, the forensic pathologist and the criminal bar.

C.K.S.

\section{AN INTRODUCTION TO PATHOLOGY}

By G. Payling Wright, D.M., F.R.C.P. Pp. $x+$ 569, illustrated. London: Longmans Green and Co. I950. 30s.

In this age of increasing specialization the bewildered teachers of medical students are incessantly bidden to integrate the curriculum, to bridge gaps and to prune the ever-growing body of knowledge with which the student is presented. At no stage is this more difficult or important than in the transition from pre-clinical to clinical studies; the abnormal must be appreciated in terms of perverted normal function. General pathology is the best medium whereby this can be accomplished. Professor Payling Wright's new book, which bears all too modest a title, succeeds admirably in its project of orientating the student in his study of the fundamental aspects of disease. Stress is laid upon the causative factors, and the mechanisms whereby structural changes are brought about are clearly explained in the light of experimental research. The text is a model of clear exposition and is excellently illustrated by photographs and diagrams. Abundant references to original papers are supplied, both recent and old, reflecting the author's appreciation of the history of the subject. About twofifths of the book is devoted to neoplastic disease and the remainder deals with the principal groups in general pathology. There is a useful chapter on tissue reactions in virus infections, and the modifying action of the antibiotics in inflammation is discussed.

The student who digests this book will be well equipped for his professional work since he will approach his patients with the essential intellectual background necessary for the interpretation of disease. There are many teachers, too, who will welcome and be helped by this modern presentation of general pathology.

D.S.R.

\section{MODERN PRACTICE IN DERMATOLOGY}

Edited by G, B. Mitchell-HegGs, O.B.E., M.D., F.R.C.P. Pp. xxv +836 , with 3 I9 illustrations and 7 coloured plates. London : Butterworth $\&$ Co. 1950. $£ 33$ s.

This impressive volume is beautifully produced with a wealth of excellent photographic illustrations.
The 50 separate chapters are the work of no less气 than 40 different authors, so it would be impossible 3 to expect a uniform quality throughout. Some of the chapters are up to date and authoritative, whilst - . others would be suitable only for undergraduate:

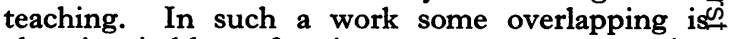
also inevitable; for instance, two consecutive chapters describe impetigo and its treatment. In both, the local use of penicillin is advocated, whichen will doubtless come in for some criticism. Histologyp is dealt with, for the most part, sketchily but throughout a practical outlook has been maintainedis

This book will not replace the present text books $\overrightarrow{0}$ being too full for the use of the average undergraduate. It will, however, be valuable to practi $-\vec{\omega}$ tioners interested in the subject, particularly tog those who are isolated from teaching centres of libraries.

\section{THE ANATOMY OF THE FEMALE PELVIS}

By F. A. Maguire, C.M.G., D.S.O., V.D., M.D. i Ch.M., F.R.C.S., F.R.A.C.S., F.R.C.O.G.ज F.A.C.S. 4th Edition. Pp. $x v+176$, with $55^{\circ}$ illustrations. London: H. K. Lewis. 1949을 $42 s$.

The author, having been for some years professor of anatomy, combines both clinical and anatomicab knowledge. The result is excellent. This fourth edition has been thoroughly revised, with addition of many new illustrations, and present detailed study of the entire pelvic anatomy. Thate of the vaginal and uterine supports is particulactyo clearly described, whilst a contribution by Dro Barrington on the examination of the gynaecologica case is thoroughly sound. The production is attractive.

This book is well worthy of study; for the⿻ student as a book of reference, for the budding gynaecologist as a constant companion.

\section{PRACTICAL PROCEDURES IN CLINICAL MEDICINE}

By R. I. S. Baylis, M.A., M.D., M.R.C.P. Pp. viī’ +445 , with 62 illustrations. London: J. and A. Churchill, Ltd. 1950. 25 s.

A generous welcome should be given to this excellent book, which fills a very real need in hos- 근 pital and general practice today.

It has been well said that dull tasks are amongst the most difficult to perform efficiently. In the field of medical writing, one can imagine few mores difficult undertakings than completing a volume on practical clinical procedures, which is both in formative and easy to read, and which bears the stamp of originality of form and presentation. Dro Bayliss has been uncommonly successful in achieveo ing all these goals which have been realized almost single-handed, and he is to be congratulated on the result of his efforts.

The reader will be surprised at the extensiveo 
field covered. Seven chapters cover procedures connected with disorders of the main systems. All are good, but the section on the nervous system might have been expanded to include tests of vestibular and auditory function. Special sections on clinical radiology, the liver, blood transfusion and the treatment of water and salt depletion will be welcomed.

The final chapter presents a miscellany of valuable information including the principles of dietetics and the technique of special procedures such as joint aspiration. Lists of normal values and conversion tables will be found useful, and those who possess a copy of this book will no longer be tormented by times and dates relating to infectious fevers; they will convert milligrams per cent. to milliequivalents in a twinkling, and they will remain calm and unharassed by the vulgar fractions of pharmacopeial dosage, which tax even the best memories.

Throughout the volume the author and his colleagues have followed an original and sound plan; the rationale of a particular procedure is first approached from a physiological angle. This is followed by a brief description of the apparatus required and the technique employed. The finat and most important paragraph deals with the interpretation of results. Instructions are clear and precise, but occasionally they suffer from the effects of multiple authorship and are contradictory (e.g. pp. 12, 123).

This book is destined for a long and useful career. As a guide to medical students it should prove invaluable but, in meeting the needs of the doctor engaged in modern hospital and general practice, it has few equals and no superior in this country today.

D.S.L.

\section{OCCUPATIONAL EYE DISEASES AND INJURIES}

By Joseph Minton, F.R.C.S. Pp. viii +184 , with 24. illustrations. London: William Heinemann. I949. 2 Is.

This book is designed to provide ophthalmologists, industrial medical officers and nursing sisters with a handbook covering the essential clinical features of the industrial hazards to which the visual apparatus is subject and the common visual problems which arise in the selection of industrial operatives. It also aims to bring home to ophthalmologists the importance of occupation as an etiological factor in ocular disease.

The book falls into three parts. The first deals with occupational injuries-mechanical, chemical and those due to radiant energy - and diseasesconjunctivitis, keratitis and the effects of various industrial solvents and poisons, and miners' nystagmus. The medico-legal problems which these various accidents arise are illustrated by case reports. The second part deals with the selection of personnel-the visual standards required for ordinary and special jobs, and the problems of the one-eyed, the blind and the partially-blind person? Thirdly are two chapters on environment-lighting and colour schemes in industry and some problems of colour vision. There are two final chapters orf. protection of the eyes.

皇

The section on mechanical injuries is largely con cerned with first-aid diagnosis and treatment thougFe the author's views on more specialized methods of treatment are outlined. The remainder of the book, from chemical injuries onwards is a fund of in $-\bar{D}$ formation to ophthalmologists on aspects of their speciality of which many of them know little. Ites is most readable, excellently illustrated, and each $\vec{b}$ chapter is provided with a bibliography. A veryminor point for criticism is the frequency with $\vec{\omega}$ which the first person singular recurs in the text.

The book is an interesting and valuable addition to ophthalmic textbooks, and is the only one of its kind in the English language.

A.L.

DISEASES OF THE NOSE AND THROAT Gु By Sir St. Clair Thomson, M.D., F.R.C.P. ஸे F.R.C.S., Ll.D., and V. E. NEGUS, M.S., F.R.C.S.o 5th Edition. Pp. xix + 1004, with 369 illustrations and 43 plates. London: Cassell \& Co. $\overrightarrow{0}$ 1948. 70s.

This is not just another edition of this wet known book. It represents a milestone in Britigh laryngology, for during its preparation the origip̧⿻ author died, and although he had done much unckerel the adverse conditions of war, the final preparation: was left to his co-author. Negus is, indeed, $++\infty$ worthy successor, but he has had to enlist the aids of a number of colleagues owing to the rapid ex $-\frac{-}{0}$ pansion of the subject and its closer association witho other branches of medicine and surgery, each morep highly technical than at the time of publication of the last edition.

Thus, there have been considerable changes in 3 parts of the book, although the general scheme remains much the same, and details of operative procedures are no longer relegated to a special chapter at the end but are appropriately included 3 . in the section dealing with the condition for which:they are most frequently performed. The section 3 . on therapeutics now includes an account of sul-î phonamide and antibiotic therapy, in which the $\frac{\text { ? }}{3}$ inadvisability of administering these powerful agents for trivial conditions is rightly stressed. There is an account of hormone and vitamin $>$ therapy, and also an article on irradiation in the treatment of new growths, where the relative merits $\mathrm{N}$ of surgery and other methods of treatment are discussed. The classification of the blood diseases $N$ has been brought up to date, and the relevant pathology described. A new section on the physi- $\omega$ ology of the nose serves to remind us of the im portance of conservation of the nasal mucosa, 0 whilst the section on nasal allergy has been expanded $\mathbb{D}$ and does much to clarify the situation, without $\stackrel{?}{+}$

denying the complexity of the subject.
The section on laryngeal palsy has been re- $\frac{0}{0}$. 